\title{
The Effects of the Family-oriented Empowerment Model on the Fatigue Level of the Patients with Chronic Obstructive Pulmonary Disease Admitted to the Hospitals Affiliated to Shahrekord University of Medical Sciences, Iran (2018)
}

\author{
Ali Hassanpour Dehkordi ${ }^{1}$, Farshad Soleymani ${ }^{2}$, Zahra Habibi ${ }^{3}$ \\ Soleyman Kheiri ${ }^{4}$, Shahriar Salehitali ${ }^{5}$
}

\begin{abstract}
Background \& Aims: Fatigue is the second most common symptom in patients with chronic obstructive pulmonary disease (COPD). Fatigue prevents carrying out individual and social roles and responsibilities and decreases people's ability to work and make efforts to maintain natural life and perform favorite and enjoyable activities. Therefore, it has many negative effects on the economic status and quality of life of those with this condition. In addition, fatigue exacerbates the disease, increases the disease load, decreases occupational productivity, ability to concentrate, and sexual function. Overcoming these issues requires the participation of the patient and the family in the disease management and care process. Moreover, caregivers' participation and ability will improve patients' health. This study aimed to evaluate the effect of a family-centered empowerment model (FCEM) on the fatigue of individuals with COPD.

Materials \& Methods: This clinical trial was performed on 72 patients with COPD accompanied by their family members. The subjects were selected by simple sampling and randomly divided into two intervention and control groups of 36. Inclusion criteria were COPD diagnosis by a physician, hospitalization of patients in internal medicine wards of hospitals affiliated to Shahrekord University of Medical Sciences, psychological health, the stability of physical condition, ability to participate in educational sessions, spirometry in the diagnostic file with $\mathrm{FEV}_{1}$ level above $35 \%$, and being literate. On the other hand, the exclusion criteria were lack of cooperation with the research, worsened clinical conditions, and inability to participate in sessions. Data were collected using a demographic characteristics questionnaire (age, gender, marital status, level of education, history of other chronic diseases, and $\mathrm{FEV}_{1}$ index), and fatigue severity scale by Crop et al. The educational program was developed based on FCEM and included four steps of perceived threat, problem-solving, educational participation and assessment. In total, four 90-minute panels were held for groups of 10-15 participants in the intervention group in the presence of their family members. In the first and second sessions, group discussions were made based on the step of the perceived threat of FCEM. In the first session, information was provided about the disease and its process, prognosis, symptoms, complications, risk factors, and failure to follow the treatment plan. The second session included a description of COPD control and prevention methods, as well as self-care behaviors and their importance. Moreover, the second and fourth sessions focused on problem-solving stages, which included detecting the problem (disease process, causative agents of the disease, and complications caused by the disease) and analyzing the problem based on the causes of diagnosis, determining goals, providing solutions, selecting the best solution, and discussing how to carry out the solution to achieve the goal according to the abilities and facilities of patients and their family members. The
\end{abstract}

\footnotetext{
1. Associate Professor, School of Nursing and Midwifery, Shahrekord University of Medical Sciences, Shahrekord, Iran

${ }^{2}$. MS Student in Nursing, Kashani Hospital, Shahrekord University of Medical Sciences, Shahrekord, Iran

${ }^{3}$. Assistant Professor, School of Medicine, Shahrekord University of Medical Sciences, Shahrekord, Iran

4. Professor, School of Health, Modeling in Health Research Center, Shahrekord University of Medical Sciences, Shahrekord, Iran

5. Assistant Professor, School of Nursing and Midwifery, Shahrekord University of Medical Sciences, Shahrekord, Iran (Corresponding author) Tel: 0913183518 
evaluation of the process during the intervention was performed by the researcher in all sessions, in a way that the patient and family members were asked about learning the material presented and the content was repeated for those who needed more explanation. Afterwards, the intervention group was followed up by the research team for three months and the questions and problems of care and the knowledge required for their care were answered. The final assessment was performed three months after the intervention by completing the fatigue questionnaire. Data analysis was performed in SPSS version 16 using frequency and percentage indexes for qualitative variables and mean and standard indexes for quantitative data with a normal distribution. Other tests applied included Fisher's exact test, Chi-square (for qualitative variables), and independent and paired t-test (for normal quantitative variables). Notably, a P-value of below 0.05 was considered statistically significant.

Results: In this study, the mean age of the participants in the intervention and control groups was $64.83 \pm 11.97$ and $62.11 \pm 6.29$ years, respectively. According to the independent t-test, there was no significant difference between the groups in terms of age $(\mathrm{P}=0.23)$. Moreover, the mean first-second rapid exhalation was reported to be $57.83 \pm 9.64$ and $58.46 \pm 11.15$ in the intervention and control groups, respectively. However, no significant difference was observed between the groups in this regard $(\mathrm{P}=0.8)$. overall, the two groups were homogenous in terms of gender, history of chronic diseases, and level of education. At the beginning of the study, the mean and standard deviation of fatigue score in the intervention and control groups was $41.10 \pm 08.58$ and 39.46 \pm 9.67 , respectively. In this respect, no significant difference was observed between the groups $(\mathrm{P}=0.5)$. After the intervention, the mean fatigue score was reported at $34.75 \pm 6.25$ and $41.7 \pm 11.83$ in the intervention and control groups, respectively, demonstrating a significant difference in this regard $(\mathrm{P}=0.01)$. According to the results, the mean fatigue score was significantly decreased in the intervention group after the intervention, compared to the control group $(\mathrm{P}=0.01)$.

Conclusion: According to the results of the study, the involvement of patients' caregivers in understanding the threats perceived from the disease and increase of their knowledge about the disease and related care will not only enhance their cooperation in the process of patient care but also will pave the way for more effective care in patients. Empowering family members responsible for the care of patients with COPD reduces the level of fatigue in these individuals. Therefore, care and treatment programs for chronic patients pay attention to patients' caregivers in addition to paying attention to the patients.

\section{Keywords: Chronic Obstructive Pulmonary Disease, Family-centered Empowerment, Fatigue}

\section{Conflict of Interest: No}

How to Cite: Hassanpour Dehkordi A, Soleymani F, Habibi Z, Kheiri S, Salehitali SH. The Effects of the Family-oriented Empowerment Model on the Fatigue Level of the Patients with Chronic Obstructive Pulmonary Disease Admitted to the Hospitals Affiliated to Shahrekord University of Medical Sciences, Iran (2018). Iran Journal of Nursing. 2020; 32(122):30-40.

Received: 9 Nov 2019

Accepted: 5 Feb 2020 


\title{
تأثير الكوى تواذمندسازى خانواده محور بر خستكى افراد مبتلابه بيمارى مزمن انسدادى

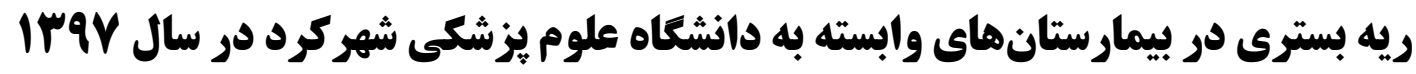

\author{
على حسن يور دهكردى'، فرشاد سليمانى '، زهرا حبيبى"، سليمان خيرى
}

جكکنه

زمينه و هدف: خستكى در بيماران مزمن انسدادى ريه بهرهورى شغلى، توانايى تمركز، قواى جنسى و عملكرد بيمار را كاهش داده و فرد را به سمت

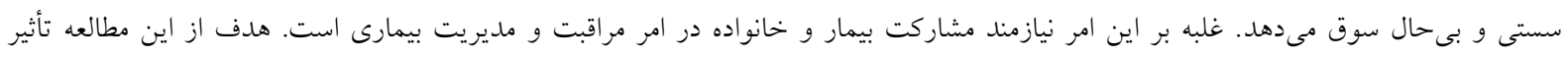

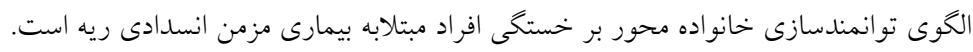

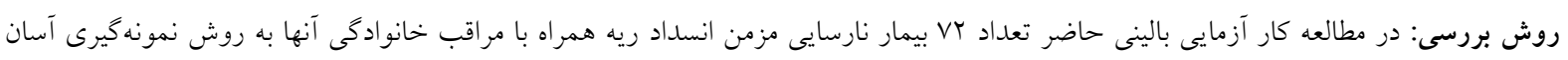

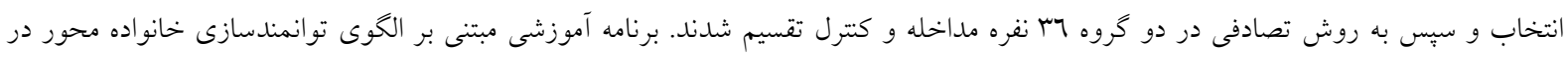

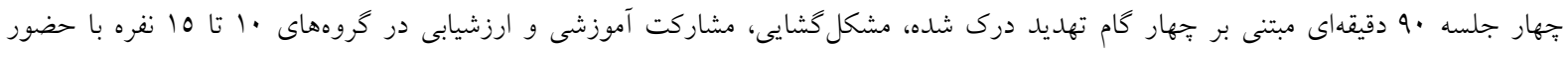

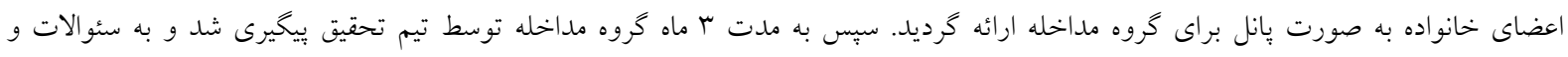

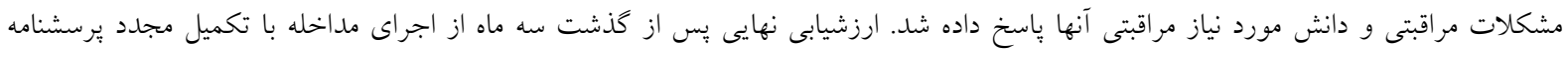

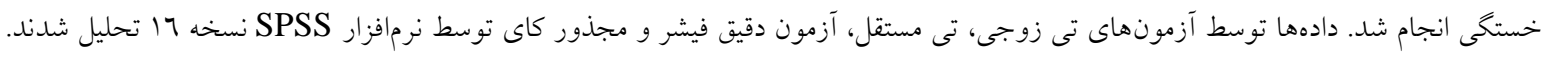

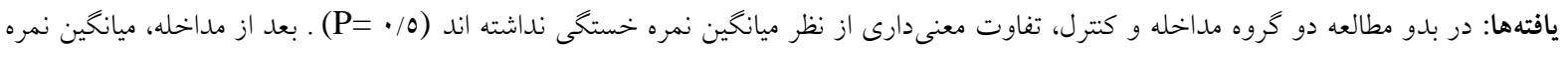

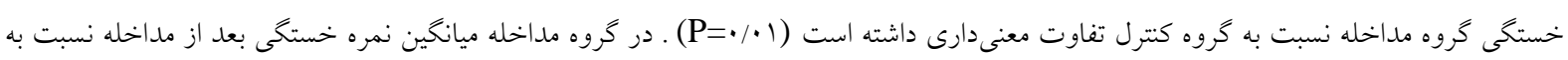

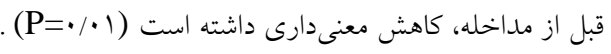
نتيجه گيرى كلى: نتايج مطالعه بيانكر آن بوده كه توانمند كردن اعضاى خانواده مسئول مراقبت بيمار نارسايى مزمن ريه ديه باعث كاهش سطح خستخى در بيماران شده است، بنابراين برنامه هاى مراقبتى و درمانى بيماران مزمن علاوه بر توجه به بيمار بايد به مراقبين بيمار نيز توجه كنند.

كليد وازهها: بيمارى مزمن انسدادى ريه، توانمندسازى خانواده محور، خستخى تعارض منافع: ندارد

تاريخ دريافت: تاريخ يذيرش:

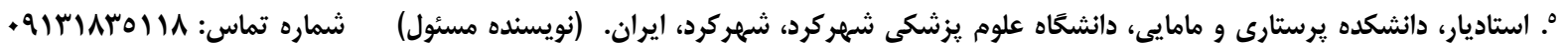



در فعاليتهاى اجتماعى ندارد و تعاملات خود را كاهش مقدمه

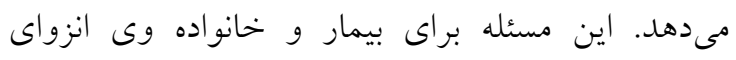

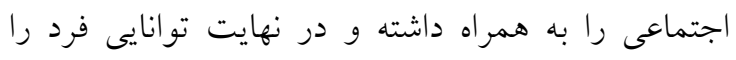

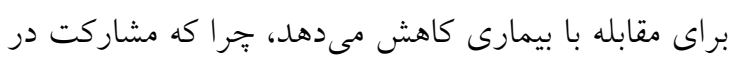

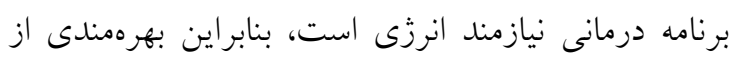

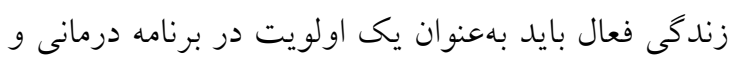

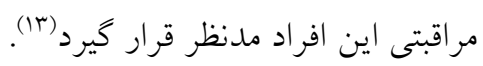

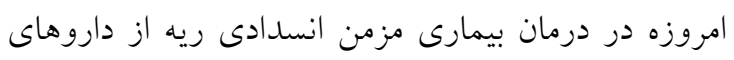

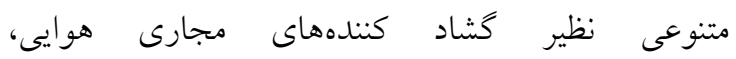

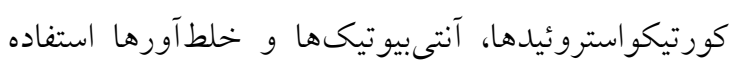
مىشود، به طورى كه با وجود دريافت درمان دارويى

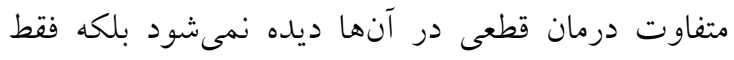

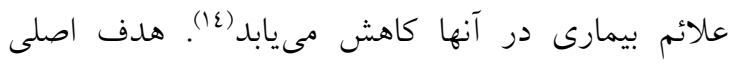
درمان عمدتاّ تسكين علائم و رسيدن فرد به بالاترين

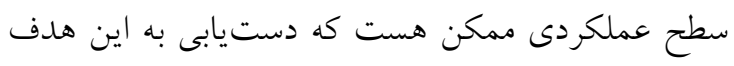

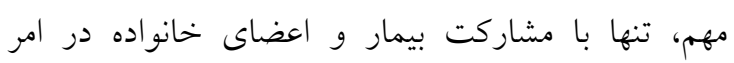
مر اقبت امكانيذير مىباشد (10). مطالعه Jonina Sigurgeirsdottir و همكاران بيانغر آن بوده كه COPD بر سلامتى جسمى و ورانى اجتماعى بيماران، روابط خانوادكى و خانواده آنها تأثير

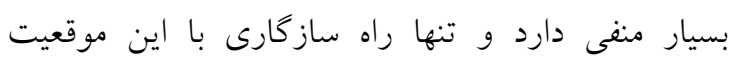
آموزش، حمايت و تو انمندى بيمار و خانو اده آنهاست (17).

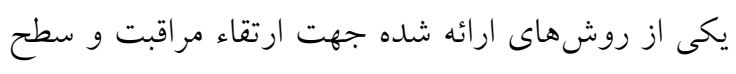
سلامت بيماران مزمن، الكوى توانمندسازى خانو اده محور است، نقطه تمركز اصلى آن، مشاركت بيمار و خانواده در

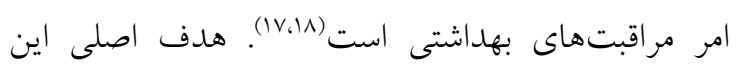
الكو توانمند كردن سيستم خانواده (بيمار و اعضاى هرائ خانواده) به منظور ارتقاء سطح سلامت آنهاست (19).

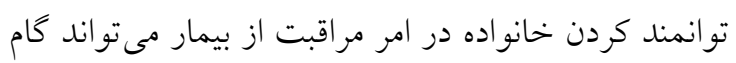

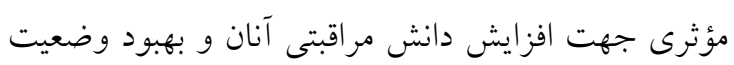

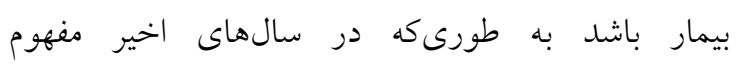

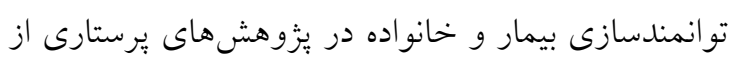

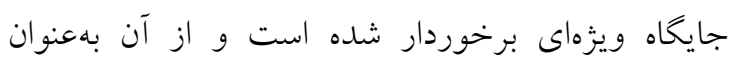

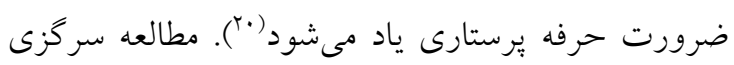

بيمارى مزمن انسدا ريه (COPD) يك بيمارى تنفسى (CO)

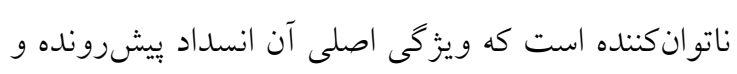

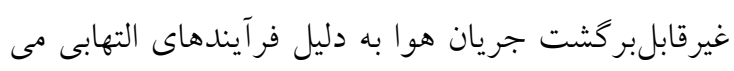

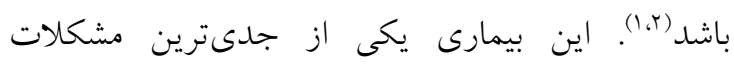

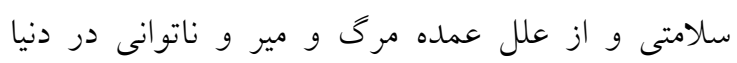

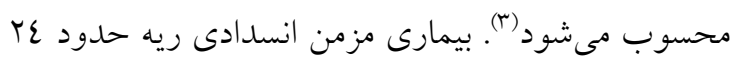

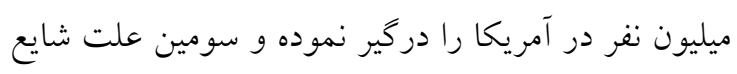

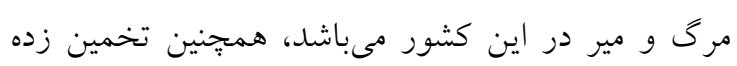

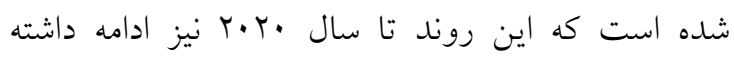

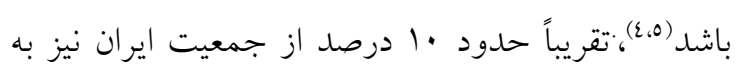
مبتلا هستند، ميزان شيوع اين بيمارى در مردان COPD

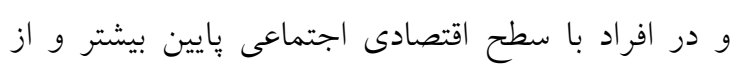

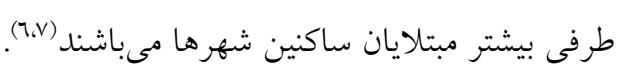

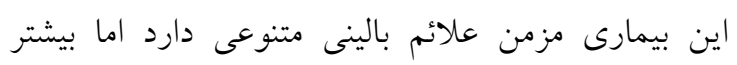

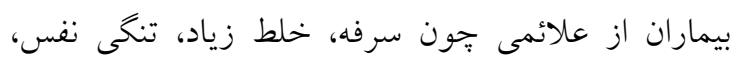

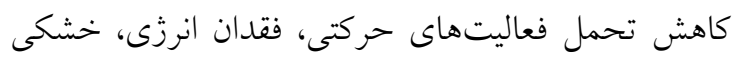

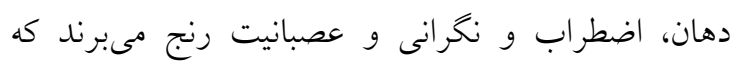
تمام جنبههاى زندكى اين بيماران را تحت تأثير قرار مى ونى دها خستخى دومين علامت شايعى است كه بيماران مبتلا به

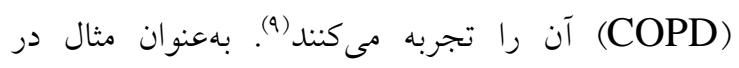
مطالعه Wong و همكاران، و 90/ درصد از بيماران مبتلا

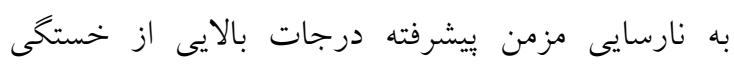

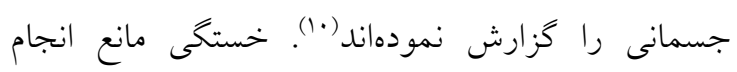

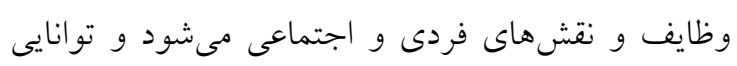

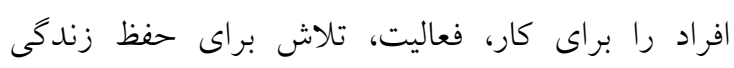

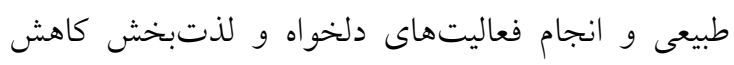

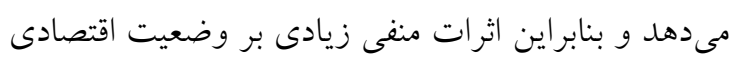

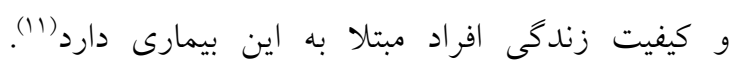
همجنين خستكى باعث تشديد وضعيت بيمارى، افزايش

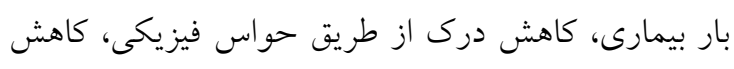

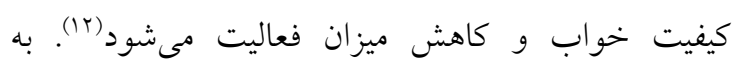
علاوه فردى كه دجار خستخى مى شود، تمايل به مشاركت 
نمونه گيرى در يك بازده زمانى 0 ماهد از بهمن IM I تا ارديبهشت رهب| انجام شد. معيارهاى ورود به مطالعه تشخيص COPD توسط بزشك، بسترى بيمار در يكى از بخشهاى داخلى بيمارستانهاى وابسته به دانشخاه علوم بزشكى شهركرد، داشتن سلامت روان، ثبات شرايط جسمانى و توانايى شركت در جلسات آموزشى، وجود اسبيرومترى در يرونده تشخيصى با سطح FEV1 بالاتر از (0\%ץ/)، و داشتن سواد خواندن و نوشتن بود. بيمارانى كه در جريان يى گيرى با محقق همكارى نكرده و يا شرايط بالينى آنها بدتر شده و توانايى شركت در جلسات را نداشتند از مطالعه خارج شدند. ابزار كردآورى اطلاعات در اين يزوهش برسشنامه ويزگ هى هاى جمعيت شناختى و يرسشنامه شدت خستخى CROP و همكاران بود. يرسشنامه ويزگ گهى هاى جمعيت شناختى و بيمارى فرد شامل سن، جنسيت، وضعيت تأهل، تحصيلات، سابقه ساير بيماريهاى مزمن و شاخص FEV1 بود. برسشنامه خستخى FSS توسط crop و همكاران در سال 1991 ارائه شد، اين :يرسشنامه شامل 9 جمله است كه به هر

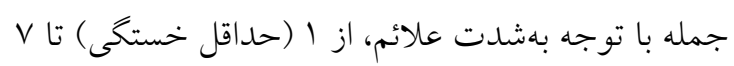
(حداكثر خستخى)، نمره داده مىشود و در كل محدوده

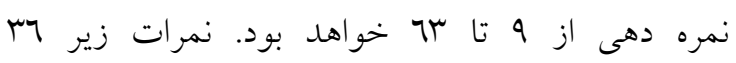
نشاندهنده عدم خستكى، مساوى و بالاتر از بـ نشاندهنده خستكى است (ع).) روايى محتوا در مطالعه

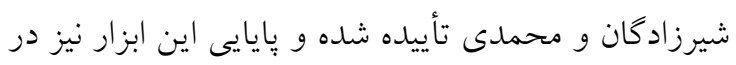

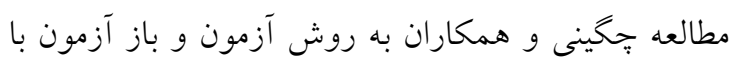
همبستخى 110/ • گزارش شده است (r0). يثزوهشخر بيرسشنامه CROP و يرسشنامه متغييرهاى جمعيت شناختى را قبل از هرگونه مداخله در هر دو كروه تكميل كرد. سبس برنامه آموزشى مبتنى بر الكوى توانمندسازى خانواده محور در جهار جلسه •9 دقيقهاى، يكبار در هفته، مبتنى بر جهار گام تهايد درك شده، مشكل گشايى، مشاركت آموزشى و ارزشيابى در گروههاى •ا تا 10 نفرى در كلاسهاى بيمارستان بسترى بيماران با حضور اعضاى خانواده يا مراقب اصلى خانواده تشكيل
شاد و همكاران با عنوان تأثير الخوى توانمندسازى خانواده محور بر كيفيت زندكى و خودكارآمدى نوجوانان مبتلا به ديابت نوع ا نتايج بيانكر آن بوده كه اجراى روشهاى آموزشى مبتنى بر توانمندسازى بيمار با

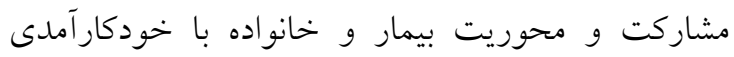

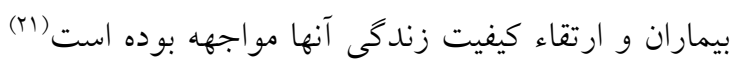
و از طرفى مطالعه لشكرى و همكاران با عنوان تعيين تأثير مدل مراقبت مشاركتى بر خستكى و كيفيت خواب بيماران همودياليزى بيانخر آن بوده ميانخين نمرات

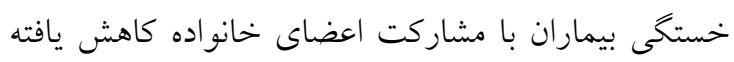

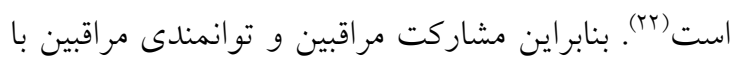
ارتقاء سلامت بيماران مواجهه بوده است. با اين وجود اين سئوال مطرح است كه آيا اين توانمندسازيى مراقبين در تمامى بيماران مزمن كاربرد دارد؟ لذا محقق تصميم به اجراى تحقيق با هدف بررسى تأثير الخوى توانمندسازى

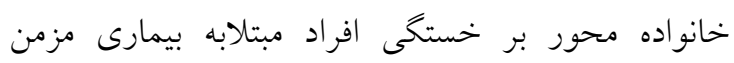
انسدادى ريه نموده است.

\section{روش بررسى}

مطالعه به صورت يك مطالعه كارآزمايى بالينى طراحى رولى

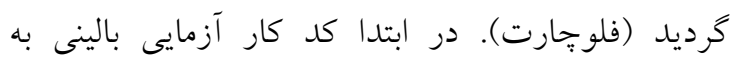

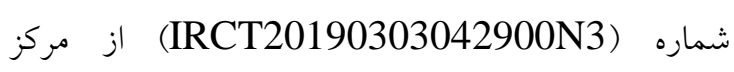

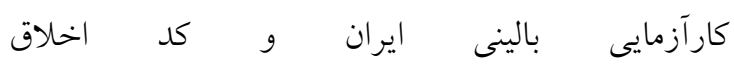
IR.SKUMS.REC.1397.254 از دانشياه علوم يزشكى شهركرد اخذ كرديد. با توجه به مطالعه ذاكرى

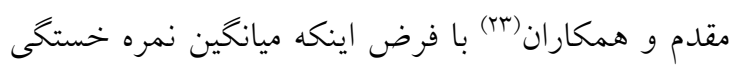
برابر با با 土 •0 باشد و طى مداخله ميانخين آن در كروه

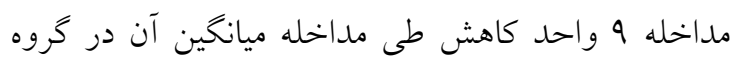
مداخله 9 واحد كاهش با در نظر كرفتن ضريب اطمينان 90 درصد و توان •N درصد، حجم نمونه در هر گروه برابر با سم نفر برآورد شد به منظور افزايش دقت و با احتمال (•(1) ريزش در هر گروه جس نفر وارد مطالعه 


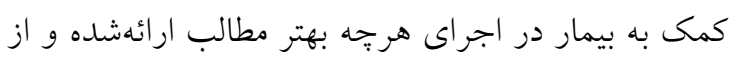

طرفى كسب اطلاعات كافى و لازم كه مىتواند بيمار را همر اهى و كمك كند، بود.
شد. در طى مداخله خانواده بيمار جندين نقش را بر عهده داشتند كه شامل همراهى بيمار براى شركت در مطالعه، كمك به بيمار جهت فراگيرى مطالب در نظر كرفته شده، دئه

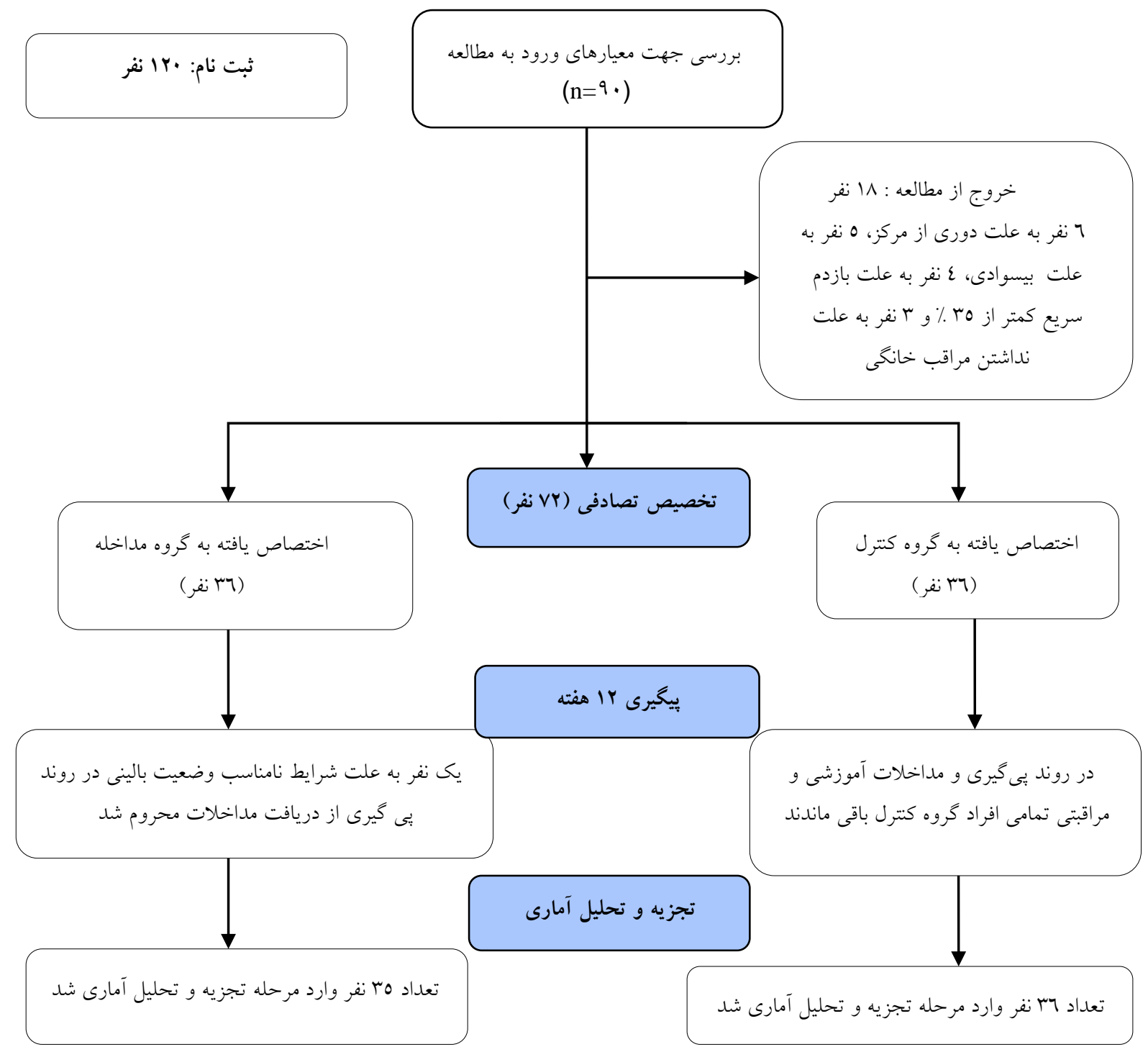

فلوجارت CONSORT

عوامل خطر و كوتاهى در يِيروى از برنامه درمان و در جلسه دوم در مورد روشهاى بيشخيرى و كنترل بيمارى

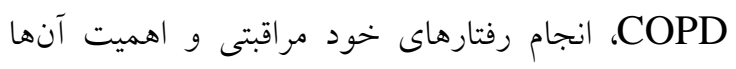

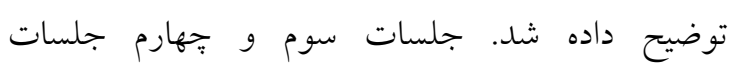

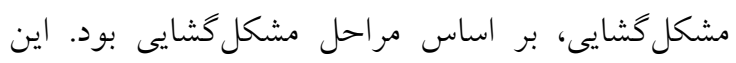

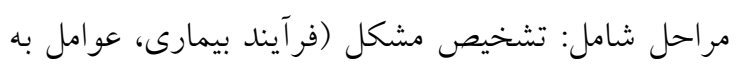

جلسات بلصورت رو در رو و جهره به جهره همراه با بحث و تبادلنظر و برسش و وِاسخ ميان بُزوهشخر، بيمار

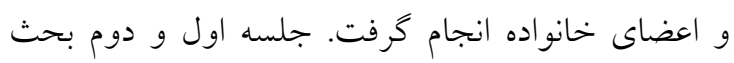

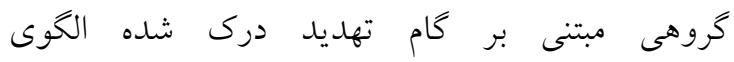

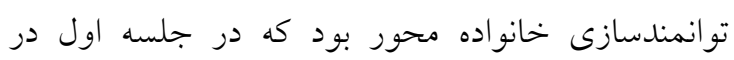

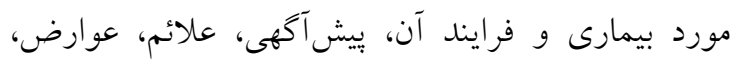


بين كروهها، براى متغيرهاى كيفى از آزمون دقيق فيشرو

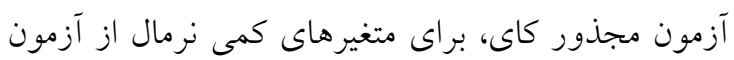

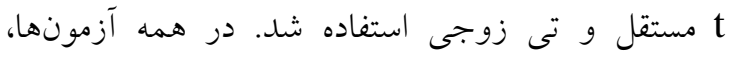

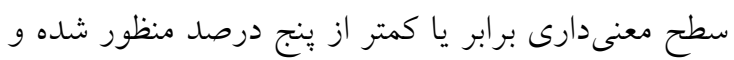

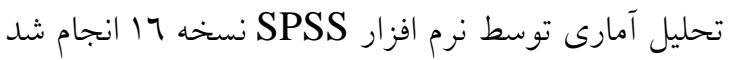

\section{يافتهها}

از VT بيمارى كه در اين مطالعه شركت داشتند يك نفر در كروه مداخله فوت كرد در نهايت مب نفر در كروه مداخله و بس نفر در گروه كنترل تا انتهاى مطالعه حضور داشتند. ميانخين سنى بيماران در كروه مداخله II/9V זم/ع7 سال و در گروه كنترل آزمون تى مستقل نشان داد دو گروه از نظر ميانخين سن درون

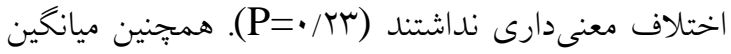

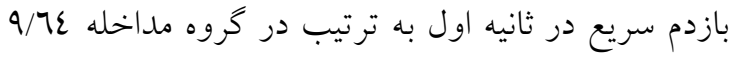

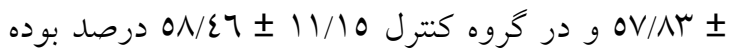
و آزمون تى مستقل نشان داد دو خروه از نظر ميانخين درصد بازدم سريع در ثانويه اول اختلاف معنى دارى

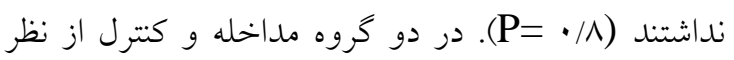
جنسيت، سابقه بيمارى مزمن و سطح تحصيلات تفاوت

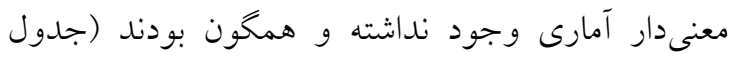

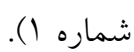

وجود آورنده بيمارى، عوارض ناشى از بيمارى) و تجزيه

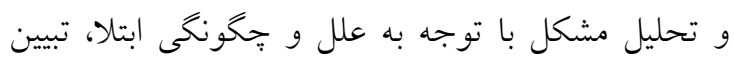

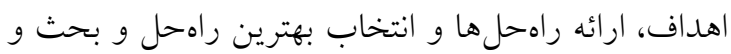
بررسى در مورد جاكونكى اجراى بهترين راهحل در جهت

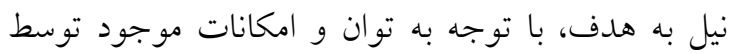

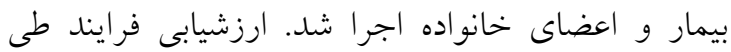
مداخله توسط محقق در تمامى جلسات صورت مى كرفت، بدين صورت كه از بيمار و اعضاى خانواده در مورد يادگيرى مطالب ارائه شده سؤال مىشد و در لدر مواردى كه نيازمند به توضيح و تشريح بهتر مطالب بود دوباره براى آنان بازگو مىشد. در مدت اجراى يُزوهش، يزوهشخر از طريق تماس تلفنى با نمونهها جهت باستخ به سؤالات و مشكلات احتمالى آنان در ارتباط بود. ارزشيابى نهايى توسط كمك يُزوهشخر پِ از كذشت سه ماه از اجراى مداخله صورت گرفت و در اين مرحله

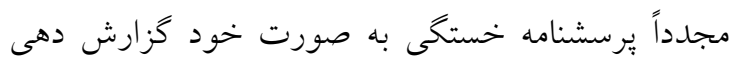
توسط بيماران هر دو گروه تكميل گرديد.

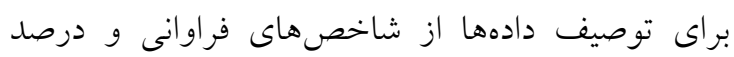
براى متغيرهاى كيفى، شاخصهاى (ميانخين I انحراف معيار) براى متغيرهاى كمى داراى توزيع نرمال استفاده شد. بررسى توزيع نرمال براى متغيرها توسط آزمون

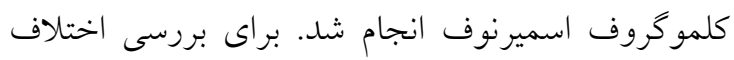

جدول شماره ا: مشخصات دموتر افيك واحدهاى مورد يزوهش (بيماران مزمن انسدادى ريه) در دو تروه مداخله و كتترل

\begin{tabular}{|c|c|c|c|c|}
\hline سطح معنى دارى & مداخله & 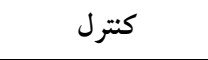 & كروهها & متغير \\
\hline$* / \pi$ & \urcorner$\Sigma / 1] \pm \wedge r / 9 \vee$ & $7 r / 7 \pm 11 / r 9$ & (انحراف معيار 土 ميانخين) & سن (سال) \\
\hline$* / 1$ & $O V / Q \pm \wedge r / \tau \varepsilon$ & $0 N / 11 \pm\{7 / 10$ & (انحراف معيار 土 ميانخين) & بازدم سريع در ثانيه اول \\
\hline \multirow[t]{2}{*}{$* * / N Y$} & $17(\varepsilon \varepsilon / \varepsilon)$ & $\operatorname{IV}(\varepsilon \wedge / 7)$ & مرد & جنس (درصد) تعداد \\
\hline & $r \cdot(00 / 7)$ & $1 \wedge(01 / \varepsilon)$ & زن ان & \\
\hline \multirow[t]{2}{*}{$* * / N r$} & $\operatorname{Tr}(7 \pi / 9)$ & $Y T(7 \cdot)$ & دارد & سابقه بيماريهاى مزمن \\
\hline & $\mathbb{1}(r \mathrm{r} / \mathrm{l})$ & $1 \varepsilon(\varepsilon \cdot)$ & 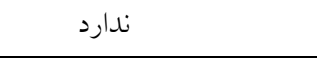 & (درصد) تعداد \\
\hline \multirow[t]{4}{*}{ 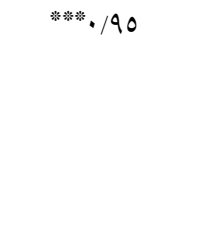 } & $1 \wedge(0 \cdot)$ & $r \cdot(O V / I)$ & خواندن و نوشتن & \\
\hline & $\wedge(Y Y / Y)$ & $7(I V / I)$ & زير ديبلم & سطح تحصيلات (درصد) تعداد \\
\hline & $7(17 / v)$ & $0(11 / \varepsilon)$ & ديڤم & \\
\hline & $\varepsilon(11 / 1)$ & $0(1 \varepsilon / \mu)$ & دانشخاهى & \\
\hline
\end{tabular}


خستخى بودند. همانطور كه مشاهده مىشود بعد از

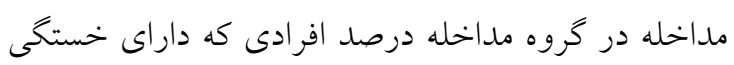

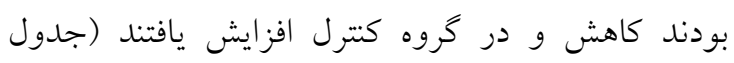

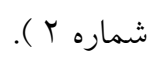

يافتهها نشان داد قبل از مطالعه در گروه مداخله بr نفر

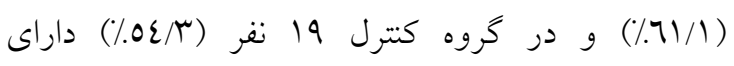
خستخى بوده در حاليكه بعد از مداخله در كروه مداخله

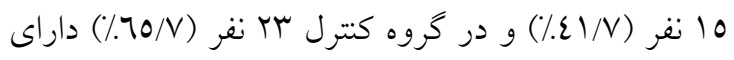

جدول شماره r: توزيع فراوانى وجود خستكى در واحدهاى مورد يزوهش (بيماران مزمن انسدادى ريه) در دو تروه كنترل و مداخله

\begin{tabular}{|c|c|c|c|c|c|c|}
\hline \multicolumn{5}{|c|}{ كرو كاما } & \multirow{3}{*}{ سطوح خستخى } & \multirow[t]{3}{*}{ زمان } \\
\hline سطح معنى دارى & \multicolumn{2}{|c|}{ مداخله } & \multicolumn{2}{|c|}{ كتترل } & & \\
\hline \multirow[t]{3}{*}{$* \cdot / r$} & درصد & ت تعداد & درصد & ت تعداد & & \\
\hline & $r_{N / 9}$ & $1 \varepsilon$ & $\varepsilon 0 / V$ & 17 & ندارد (كمتر از רس) & قبل از مداخله \\
\hline & $71 / 1$ & rr & $0 \varepsilon / \Gamma$ & 19 & دارد (דr و بيشتر ) & \\
\hline \multirow[t]{2}{*}{$* \cdot / \cdot r$} & $O N / r$ & $r$ & $r \varepsilon / r$ & Ir & ندارد (كمتر از حr) & بعد از مداخله \\
\hline & $\varepsilon 1 / V$ & 10 & $70 / \mathrm{V}$ & $r$ & دارد (דس و بيشتر ) & \\
\hline
\end{tabular}

مستقل نشان داد بين دو گروه از نظر خستخى اختلاف

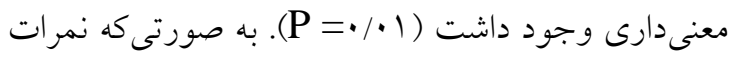

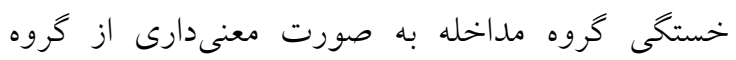

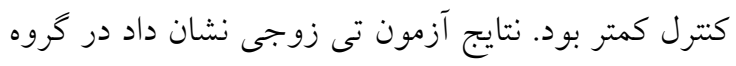

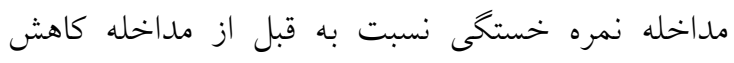
معنى دارد (P=/(P

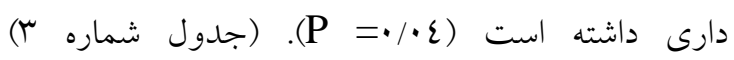

ميانگين و انحراف معيار نمره خستخى قبل از مداخله به

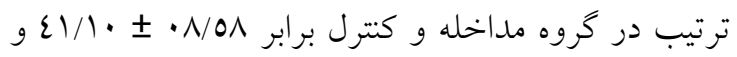
1 9/27 9/7V

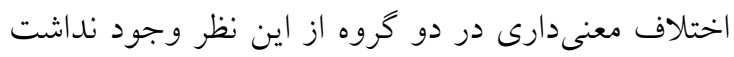

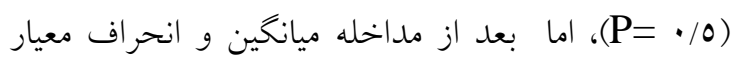

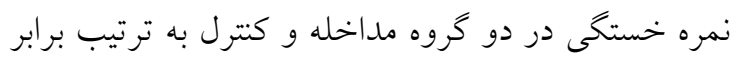

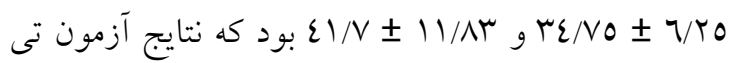

جدول سّ: ميانكَين و انحراف معيار خستكى در واحدهاى مورديزوهش (بيماران مزمن انسدادى ريه) در دو تَروه مداخله و كنترل

\begin{tabular}{|c|c|c|c|}
\hline سطح معنى دارى & كترل & 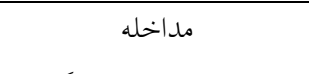 & كروه \\
\hline بين كروهى" & (انحراف معيار 土 ميانكين) & (انحر اف معيار 土 ميانكين) & مان \\
\hline$. / 0 . r$ & $r q / 27 \pm q / 7 V$ & $\{1 / \cdot \wedge \pm 1 \cdot / 01$ & قبل از مداخله \\
\hline \multirow[t]{2}{*}{.$/ \cdot 1$} & $\varepsilon / N \pm V / \wedge r$ & reNo $\pm T / r_{0}$ & بعد از مداخله \\
\hline & $\cdot / \cdot \varepsilon$ &.$/ \cdot 1$ & سطح معنى دارى (درون كروهى)*** \\
\hline.$/ \cdot 1$ & $1 / 7 V \pm r / 1 r$ & $-7 / \Gamma \pm \tau / \cdot 0$ & تغييرات ميانكين * \\
\hline
\end{tabular}

خانواده محور بر سطح خستخى در بيماران داراى بيمارى

$$
\text { مزمن انسداد ريه بوده است. }
$$

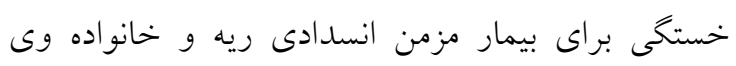

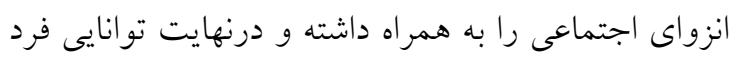

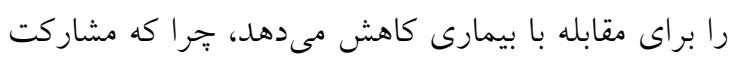

\section{بحث و نتيجه كيرى}

مقايسه ميانخين و تغييرات ميانخين نمره خستخى قبل قبل و و

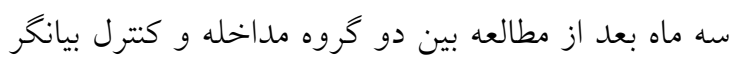

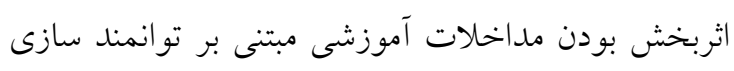


توانمندى شيردهى مادران كروه مداخله در دو هفته و دو

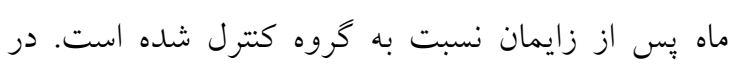

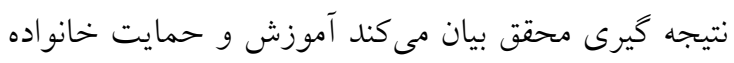

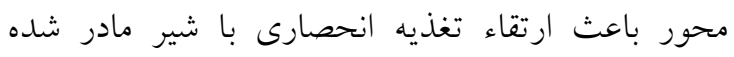

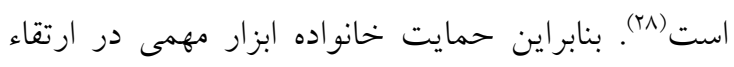
سطح سلامت و افزايش عملكرد ساير اعضاى خانواده

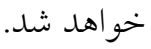
مطالعه Jonina Sigurgeirsdottir و همكاران تلد بان عنوان تجارب بيماران داراى بيمارى مزمن انسدادى ريه و

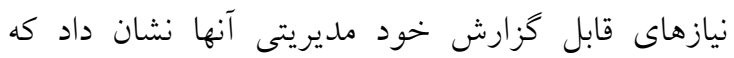
COPD بر سلامتى جسمى و روانى - اجتماعى بيماران،

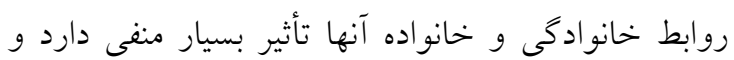

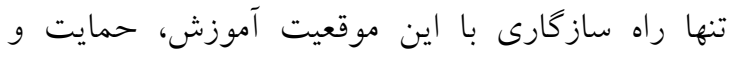
توانمندى بيماران و خانواده آنهاست(17). نتيجه مطالعه فوق بيانكر آن است كه دخالت مراقبان بيماران در درى تهايدات ناشى از بيمارى و از طرفى افزايش دانش آنها

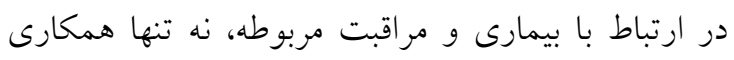

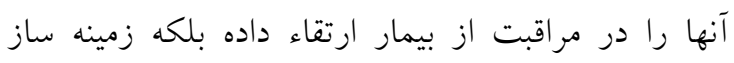

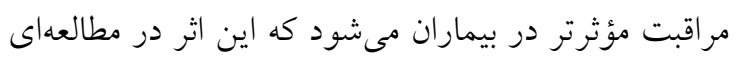

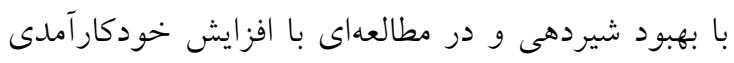

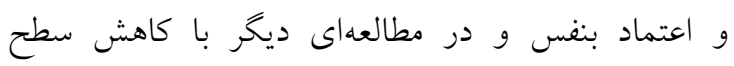
خستكى بيماران نمود يافته است.

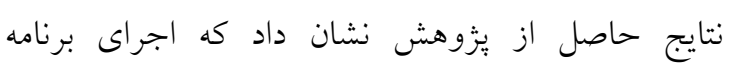

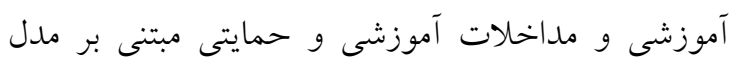

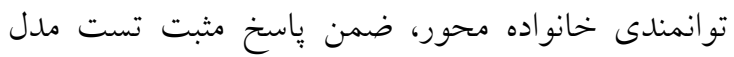

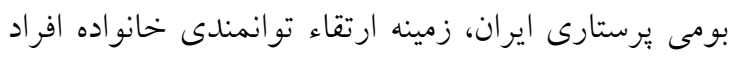

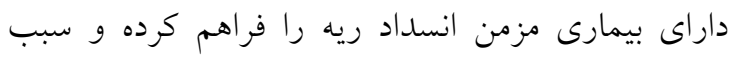
كاهش سطح خستخى در بيماران مزمن ريه مى شود. بنابراين توجه به اين مدلها در ارائه مراقبتهاى يرستارى يكى ضرورت جدى در ارتقاء سطح مراقبت در بيماران

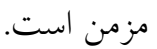

تعارض منافع: نويسندكان مقاله هيجگگ نه تعارض منافع

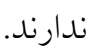

در برنامه درمانى نيازمند انرزى است. بنابراين بهرهمندى

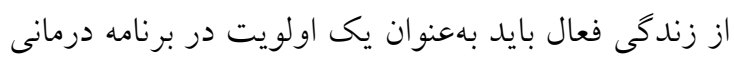

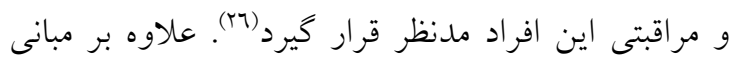

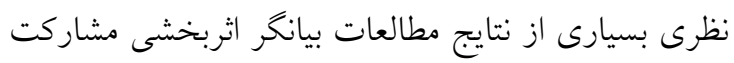

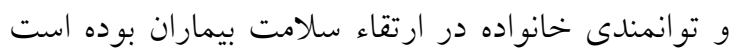

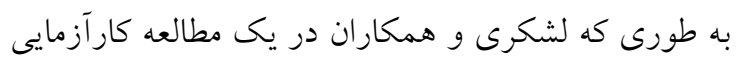

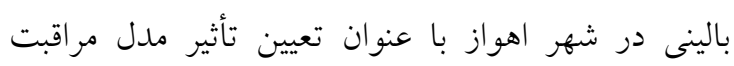

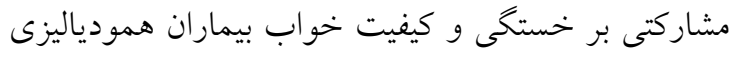

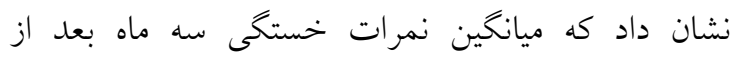

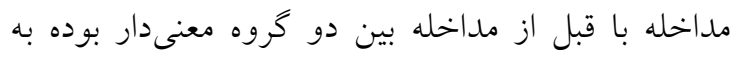

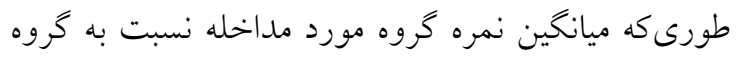
كنترل با كاهش معنى دارى مواجهه بوده است (rr). نتايج

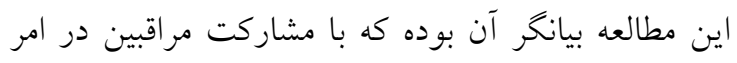

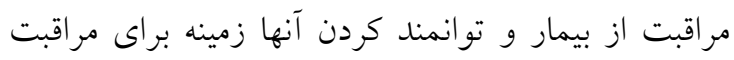
اثربخشتر براى بيمار فراهم خواهد شد.

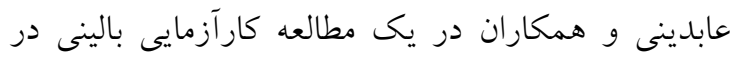

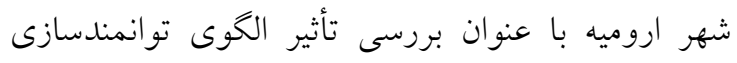

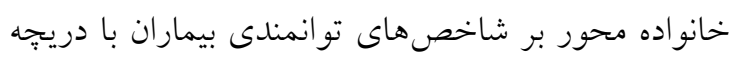

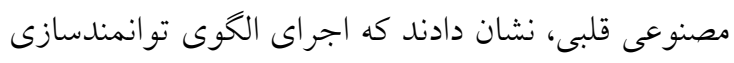
خانواده محور موجب بهبود شاخصى هاى توانمندى در در درى

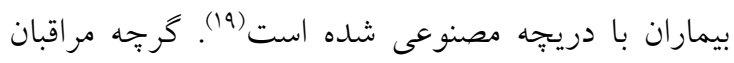

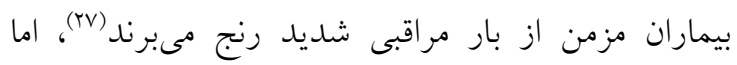

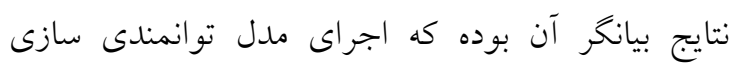

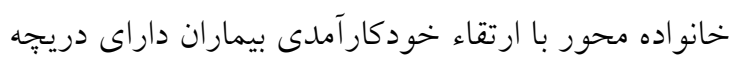
مصنوعى، كاهش سطح خستخى در بيماران همودياليز و بيماران مزمن انسداد ريه مواجهه بوده لذا توانمند كردن سئن

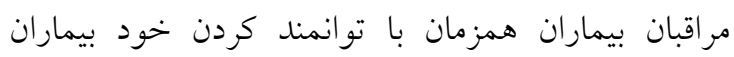
زمينه اثر بخشى بهتر در بيماران و كاهش مشكلات مرتبط با بيمارى در بيماران بوده است.

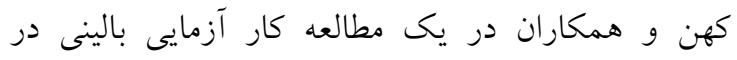
اصفهان با عنوان تأثير آموزش و حمايت خهان خانواده محور

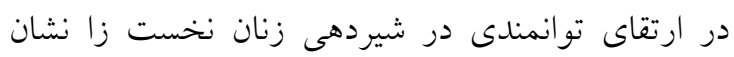
دادند كه آموزش و حمايت خانواده محور در زنان نمان نخست زا باعث افزايش معنىدارى در ميانخين نمره 


$$
\begin{aligned}
& \text { يزشكى شهركرد به خاطر حمايت مالى طرح و همجنين }
\end{aligned}
$$

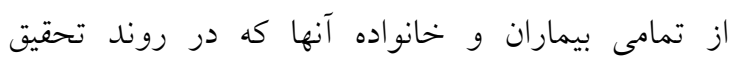

$$
\begin{aligned}
& \text { همكارى كامل داشتهاند، تقدير و تشكر مىنماييم. }
\end{aligned}
$$

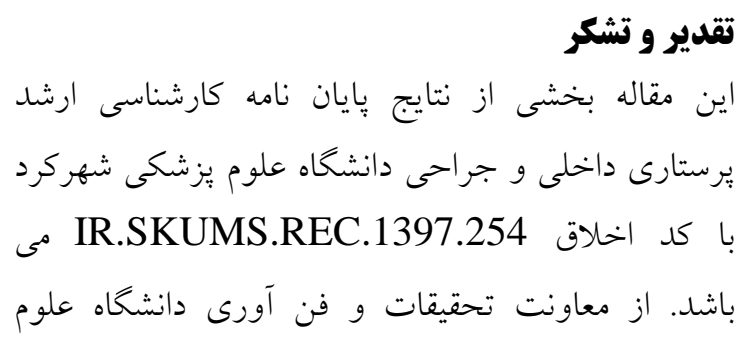

\section{References}

1. Nunes DM, Mota RM, Machado MO, Pereira ED, De Bruin VM, De Bruin PF. Effect of melatonin administration on subjective sleep quality in chronic obstructive pulmonary disease. Brazil J Med Biolog Research. 2008;41(10):926-31.

2. Kasper D, Fauci A, Hauser S, Longo D, Jameson J, Loscalzo J. Harrison's principles of internal medicine, 19e. Mcgraw-hill; 2015.

3. Monjazebi F, Dalvandi A, Ebadi A, Khankeh HR, Rahgozar M, Richter J. Psychometric properties of instruments measuring activities of daily living in Patients with COPD: A systematic review. COPD. 2014;13(4):9. [Persian]

4. Vogelmeier CF, Criner GJ, Martinez FJ, Anzueto A, Barnes PJ, Bourbeau J, Celli BR, Chen R, Decramer M, Fabbri LM, Frith P. Global strategy for the diagnosis, management, and prevention of chronic obstructive lung disease 2017 report. GOLD executive summary. Am J Respir Critical Care Med. 2017;195(5):557-82.

5. Budhiraja R, Parthasarathy S, Budhiraja P, Habib MP, Wendel C, Quan SF. Insomnia in patients with COPD. Sleep. 2012;35(3):369-75.

6. Abedi H, Salimi SJ, Feizi A, Safari S. Effect of self-efficacy enhancement program on self-care behaviors in chronic obstructive pulmonary disease. Iranian journal of nursing and midwifery research. 2013;18(5):421-4. [Persian]

7. Naghavi M. Etiology of death in 18 provinces of Iran in year 2001. Tehran: Ministry of Health and Medical Education IR Iran. 2003;21 . [Persian]

8. Blinderman CD, Homel P, Billings JA, Tennstedt S, Portenoy RK. Symptom distress and quality of life in patients with advanced chronic obstructive pulmonary disease. J Pain Symptom Manag. 2009;38(1):115-23.

9. Şahin ZA, Dayapoğlu N. Corrigendum to" Effect of progressive relaxation exercises on fatigue and sleep quality in patients with chronic obstructive pulmonary disease (COPD)"[Complement. Ther. in. Clin. Pract. 21 (2015) 227-281]. Complementary therapies in clinical practice. 2018;31:389.

10. Şahin ZA, Dayapoğlu N. Effect of progressive relaxation exercises on fatigue and sleep quality in patients with chronic obstructive lung disease (COPD). Complementary therapies in clinical practice. 2015;21(4):277-81.

11. Wong CJ, Goodridge D, Marciniuk DD, Rennie D. Fatigue in patients with COPD participating in a pulmonary rehabilitation program. International journal of chronic obstructive pulmonary disease. 2010; 5:319.

12. Spruit MA, Vercoulen JH, Sprangers MA, Wouters EF. Fatigue in COPD: an important yet ignored symptom. The Lancet Respiratory Medicine. 2017;5(7):542-4.

13. Kentson M, Tödt K, Skargren E, Jakobsson P, Ernerudh J, Unosson M, Theander K. Factors associated with experience of fatigue, and functional limitations due to fatigue in patients with stable COPD. Therapeutic advances in respiratory disease. 2016;10(5):410-24.

14. Hosseinzadeh Yonesi E, Mircheraghi F, Mohammdzadeh Moghadam H, Mojalli M. Effect of Thymus Vulgaris Inhaling on Wheezing and Respiratory Rate in Patients with Acute Exacerbation of Chronic Obstructive Pulmonary Disease. The Horizon of Medical Sciences. 2018;24(1):29-34. [Persian]

15. Etemadi Sanandaji M, Ghahri Sarabi A, Bonakdar H, Akbarzade Baghban A, Banaderakhshan $\mathrm{H}$, Ghasemi S. Comparison of impact of face to face and educational booklet methods on respiratory self efficacy of patients with chronic obstructive pulmonary disease attending to 
selected hospitals of Shahid Beheshti university of medical sciences in Tehran. Journal of Nursing Education. 2015;4(1):1-7. [Persian]

16. Sigurgeirsdottir J, Halldorsdottir S, Arnardottir RH, Gudmundsson G, Bjornsson EH. COPD patients' experiences, self-reported needs, and needs-driven strategies to cope with selfmanagement. Int J Chronic Obstruct Pulm Dis. 2019;14:1033.

17. Jokar Z, Mohammadi F, Khankeh HR, Fallah Tafti S. Effect of home-based pulmonary rehabilitation on fatigue in patients with COPD. Journal of hayat. 2013;18(5):64-72 . [Persian]

18. Masoudi R, Soleimani M, Hasheminia A, Qorbani M, HasanPour-Dehkordi A, Bahrami N. The effect of family centered empowerment model on the quality of life in elderly people. The journal of Qazvin University of medical sciences. 2010;14 . [Persian]

19. Abedini F, Zareiyan A, Alhani F, Teimouri F. The implementation of family-centered empowerment model on the empowerment parameters of patients with prosthetic heart valves. Military Caring Sciences. 2016;3(3):174-83. [Persian]

20. Kheirollahi N, Khatiban M, Oshvandi K, Alhani F, Faradmal J. The effect of family-centered empowerment intervention on perceived severity of threat in caregivers of patients with stroke: a semi experimental study. Avicenna Journal of Nursing and Midwifery Care . 2014;22(3):74-82. [Persian]

21. Sargaz Shad T, Kermansaravi F, Navidian A. Effect of the Family-Centered Empowerment Model on Quality of Life and Self-Efficacy in Adolescents with Type 1 Diabetes Referring to the Ali Asghar's Clinic in Zahedan. Iranian Journal of Endocrinology and Metabolism. 2016; 19(5) 21-30. [Persian]

22. Farhad L, Brazparandjani S, Latifi SM, Chahkhoei M, Khalili A, Paymard A, Dehghani F, Shariati A. The effect of collaborative care model on the fatigue in patients undergoing maintenance hemodialysis: A randomized clinical trial. Qom University of Medical Sciences Journal. 2016;10(8):71-9. [Persian]

23. Zakerimoghadam M, Shaban MA, Kazemnejad AN, Kh T. The effect of breathing exercises on fatigue level of COPD patients. Journal of hayat. 2006;12(3):17-25. [Persian]

24. Neuberger GB. Measures of fatigue: the fatigue questionnaire, fatigue severity scale, multidimensional assessment of fatigue scale, and short form-36 vitality (energy/fatigue) subscale of the short form health survey. Arthritis Care \& Research: Official Journal of the American College of Rheumatology. 2003;49(S5):S175-83.

25. Xue XL, Wang TF, Yu CG. Estimation on the reliability and validity of the fatigue selfassessment scale. Chinese Journal of Integrated Traditional and Western Medicine. 2008;28(6):550-4.

26. Chegeni PS, Gholami M, Azargoon A, Pour AH, Birjandi M, Norollahi H. The effect of progressive muscle relaxation on the management of fatigue and quality of sleep in patients with chronic obstructive pulmonary disease: A randomized controlled clinical trial. Complementary therapies in clinical practice. 2018; 31:64-70.

27. Salehitali S, Ahmadi F, Dehkordi AH, Noorian K, Fereidooni-Moghadam M, Zarea K. Progressive exhaustion: A qualitative study on the experiences of Iranian family caregivers regarding patients undergoing hemodialysis. Int J Nurs Sci. 2018;5(2):193-200.

28. Kohan S, Heidari Z, Keshvari M, Dolati A. Promoting Breastfeeding Empowerment in Primiparus Women: Effect of Family-Center Education and Support. Daneshvar Medicine. 2016;24(125):51-8. [Persian] 